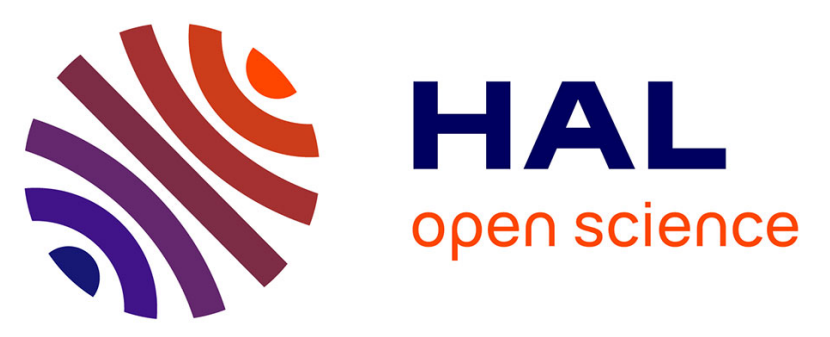

\title{
Structural and optical properties of nanodots, nanowires, and multi-quantum wells of III-nitride grown by MOVPE nano-selective area growth
}

W.H. Goh, G. Patriarche, P.L. Bonanno, S. Gautier, T. Moudakir, M. Abid, G. Orsal, A.A. Sirenko, Z.-H. Cai, A. Martinez, et al.

\section{To cite this version:}

W.H. Goh, G. Patriarche, P.L. Bonanno, S. Gautier, T. Moudakir, et al.. Structural and optical properties of nanodots, nanowires, and multi-quantum wells of III-nitride grown by MOVPE nano-selective area growth. Journal of Crystal Growth, 2011, 315 (1), pp.160-163. 10.1016/j.jcrysgro.2010.08.053 . hal-00554254

\section{HAL Id: hal-00554254 \\ https://hal.science/hal-00554254}

Submitted on 2 Dec 2021

HAL is a multi-disciplinary open access archive for the deposit and dissemination of scientific research documents, whether they are published or not. The documents may come from teaching and research institutions in France or abroad, or from public or private research centers.
L'archive ouverte pluridisciplinaire HAL, est destinée au dépôt et à la diffusion de documents scientifiques de niveau recherche, publiés ou non, émanant des établissements d'enseignement et de recherche français ou étrangers, des laboratoires publics ou privés.

\section{(ㄷ)(1) $\$$}

Distributed under a Creative Commons Attribution - NonCommerciall 4.0 International 


\title{
Structural and optical properties of nanodots, nanowires, and multi-quantum wells of III-nitride grown by MOVPE nano-selective area growth
}

\author{
W.H. Goh ${ }^{\text {a,* }}$, G. Patriarche ${ }^{\text {b }}$, P.L. Bonanno ${ }^{\text {a }}$, S. Gautier ${ }^{c}$, T. Moudakir ${ }^{c}$, M. Abid $^{\text {a }}$, G. Orsal ${ }^{\text {c }}$, A.A. Sirenko ${ }^{\text {d }}$, \\ Z.-H. Cai ${ }^{\mathrm{e}}$, A. Martinez ${ }^{\mathrm{b}}$, A. Ramdane ${ }^{\mathrm{b}}$, L. Le Gratiet ${ }^{\mathrm{b}}$, D. Troadec $^{\mathrm{f}}$, A. Soltani ${ }^{\mathrm{f}}$, A. Ougazzaden ${ }^{\mathrm{a}}$ \\ a Georgia Institute of Technology/GT-Lorraine-UMI 2958, Georgia Tech-CNRS, Metz 57070, France \\ ${ }^{\mathrm{b}}$ Laboratoire de Photonique et de Nanostructures, CNRS Marcoussis 91460, France \\ c Laboratoire Matériaux Optiques, Photonique et Micro-nano Systèmes, UMR CNRS 7132, Université de Metz et Supélec, Metz 57070, France \\ ${ }^{\mathrm{d}}$ Department of Physics, New Jersey Institute of Technology, NJ 07102, USA \\ e Advanced Photon Source, Argonne 60439, USA \\ Institut d'Electronique, de Microélectronique et de Nanotechnologie, Villeneuve d'Ascq Cedex 59652, France
}

\begin{abstract}
Nanodots, nanowires, and semi-polar quantum well structures of GaN-based material have been grown by nano-selective area growth (NSAG). The growth evolution of the nanostructure has been studied. Cross-sectional transmission electron microscopy (TEM) shows that the nanostructures are free of threading dislocations. The growth of AlGaN/GaN layers is uniform and shows sharp interfaces between the AlGaN and GaN epilayers. AlGaN nanodots/nanowires, which are formed at the apexes of the nano-pyramids/nano-ridges, are found to be homogeneous in size and to have a higher aluminum mole fraction than the surrounding material. In contrast, the InGaN/GaN growth shows no quantum dots at the apexes of the nanostructures. We found that the growth facets of different Miller's indices are formed on the InGaN/GaN nano-ridges. Energy dispersive Xray spectroscopy (EDX) shows higher indium incorporation at the intersection of the growth facets. Cathodoluminescence measurements show enhanced luminescence intensity from InGaN multi-quantum wells (MQWs) grown on the nanostructure compared to that from InGaN MQWs grown on an unpatterned area.
\end{abstract}

\section{Introduction}

Low dimensional nitrides structures such as quantum dots (QDs) have attracted much attention for light emitting devices such as laser diodes due to enhanced carrier confinement and to temperature stability of the threshold current [1]. In addition, the strong exciton binding energies in the nitride compounds make them suitable for single-dot emitters. However, these applications require QDs with homogeneous size distribution, a precise control of position, and a high areal density of dots, which cannot be provided by self-assembly in the Stranski-Krastanow growth mode [2]. Additionally, it has been reported that quantum well structures grown on non-polar or semi-polar GaN facets show a reduced piezoelectric field effect $[3,4]$. However, non-polar or semi-polar layers grown on foreign substrates such as $r$-plane sapphire and $m$-plane $\mathrm{SiC}$ typically have very high densities of stacking faults and defects $[5,6]$.

Recently, selective area growth (SAG) has been shown to be a powerful approach to grow not only QDs $[7,8]$ at the apex of a

\footnotetext{
* Corresponding author. Tel.:+3306268594 65; fax:+330387203940.

E-mail address: wgoh@georgiatech-metz.fr (W.H. Goh).
}

pyramid but also quantum well structures on semi-polar planes $[9,10]$. Until now, most of the reported QDs and quantum wells have been produced by SAG with a typical in-plane size on the micrometer scale. SAG on the nanoscale on the other hand offers advantages such as a 3-D stress relief mechanism [11], extremely low defect density, an increase of areal density of the dots, and an increase of light emitting area. In this work, we study the nanodots, nanowires, and semi-polar quantum well structures produced by nano-selective area growth (NSAG). Their structural and optical properties will be discussed.

\section{Experimental procedure}

The NSAG of GaN-based materials are performed in a metalorganic vapor phase epitaxy (MOVPE) T-shaped reactor [12]. First, a $\mathrm{SiO}_{2}$ dielectric mask with a thickness of $100 \mathrm{~nm}$ is deposited on a $\left(\begin{array}{llll}0 & 0 & 0 & 1\end{array}\right)$-oriented $\mathrm{GaN} / \mathrm{Al}_{2} \mathrm{O}_{3}$ template using chemical vapor deposition. The thickness of $\mathrm{GaN}$ is $3.5 \mu \mathrm{m}$ and the threading dislocation density is $5 \times 10^{8} \mathrm{~cm}^{-2}$. Electron-beam lithography and reactive ion etching are then used to pattern the $\mathrm{SiO}_{2}$ mask on the template. The nano-openings are $80 \mathrm{~nm}$ in 
diameter and the windows of the nano-stripes $(0.12 \mu \mathrm{m} \times 7.6 \mu \mathrm{m})$ are defined in two different directions, $\left\langle\begin{array}{llll}1-1 & 0 & 0\rangle\end{array}\right.$ and $\left\langle\begin{array}{llll}1 & 1-2 & 0\end{array}\right\rangle$. The nano-openings and nano-stripes act as nucleation sites for the subsequent growth of the GaN nano-pyramid and nano-ridge structures, respectively. MOVPE growth is carried out under nitrogen ambient. Trimethylindium, trimethylgallium, trimethylaluminum, and ammonia are used as the sources of indium, gallium, aluminum, and nitrogen, respectively. The total reactor pressure is fixed at $13.3 \mathrm{kPa}$. The growth rate is kept relatively low to obtain high crystal quality and perfect selectivity.

Growth starts with NSAG of GaN at $1000{ }^{\circ} \mathrm{C}$ until the faceted pyramid and ridge structures are obtained. This growth is then followed by either $\mathrm{AlGaN} / \mathrm{GaN}$ layers (grown at $1000{ }^{\circ} \mathrm{C}$ ) or InGaN/GaN layers (grown at $800{ }^{\circ} \mathrm{C}$ ) deposited at the top of the nano-pyramids and nano-ridges. To study the growth evolution of the AlGaN/GaN nanostructure, AlGaN thin layers are occasionally deposited for $1 \mathrm{~min}$ to act as a marker. The first few AlGaN markers are deposited during 3, 6, 11, and 16 min of growth. The subsequent AlGaN markers are grown every 15 min. Surface morphology of the faceted nanostructures is characterized by scanning electron microscopy (SEM). Cross-sectional TEM and synchrotron-based submicron beam X-ray diffraction (XRD) are used to study the structural properties. Room temperature spot mode cathodoluminescence $(\mathrm{CL})$ is used to characterize the optical properties of the nanostructures.

\section{Results and discussion}

Fig. 1 shows the SEM images of a nano-pyramid and several nano-ridges grown by NSAG. The selectively grown structures are very well faceted because of the anisotropy of growth rate along different crystallographic planes. For the nano-pyramid, the growth fronts consist of six $\left\{\begin{array}{llll}1 & -1 & 0 & 1\end{array}\right\}$ facets. AFM measurements (not shown here) show that dimensions of the pyramids and ridges are uniform over the whole patterned area.

To investigate the threading dislocations and growth evolution of the nanostructures, TEM has been employed. A bright field TEM image of a nanostructure is presented in Fig. 2a. This TEM image shows the absence of threading dislocations in the nanostructure grown by NSAG. The reduction of dislocation density in the nanostructure is due to the small size of the openings (on the order of a few nanometers), which causes most of the threading dislocations in the template to be interrupted by the dielectric mask as shown in Fig. 2a. The growth evolution of the nanostructure (nano-ridge and nano-pyramid) is studied by high angle annular dark field (HAADF) TEM. The growth starts with the formation of a truncated pyramid structure as shown by the AlGaN markers in Fig. 2b. The growth rate in the $c$-plane direction is higher than the growth rate on the side facets. This leads to the formation of a complete pyramid with six $\left\{\begin{array}{lll}1-1 & 0 & 1\end{array}\right\}$ facets. After the nano-opening is filled, the growth occurs laterally over the top of the dielectric mask while maintaining the pyramidal shape.

A HAADF TEM image of the AlGaN/GaN NSAG structure is shown in Fig. 3. The thickness of the AlGaN layers has been estimated from the TEM image to be about 2.5 monolayers or $\sim 0.65 \mathrm{~nm}$. The growth is highly uniform and the image contrast shows a sharp and flat interface between the AlGaN and GaN epilayers. The nanodots and nanowires form at the top of the nano-pyramid and nano-ridge, respectively. The nanowires grown on the nano-ridge are very homogeneous in size with a height of about $2.5 \mathrm{~nm}$ and width of $6 \mathrm{~nm}$ as shown in Fig. 3. EDX shows about $8 \%$ aluminum incorporation at the apexes of both nanopyramids and nano-ridges.

To further investigate the structural properties and the incorporation of aluminum in the nanostructure, synchrotron based submicron a

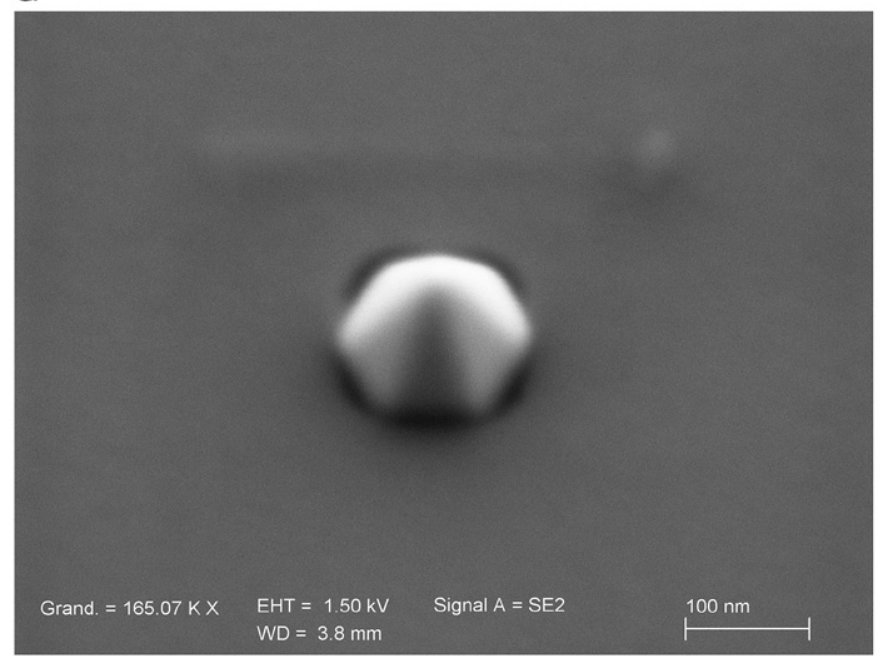

b

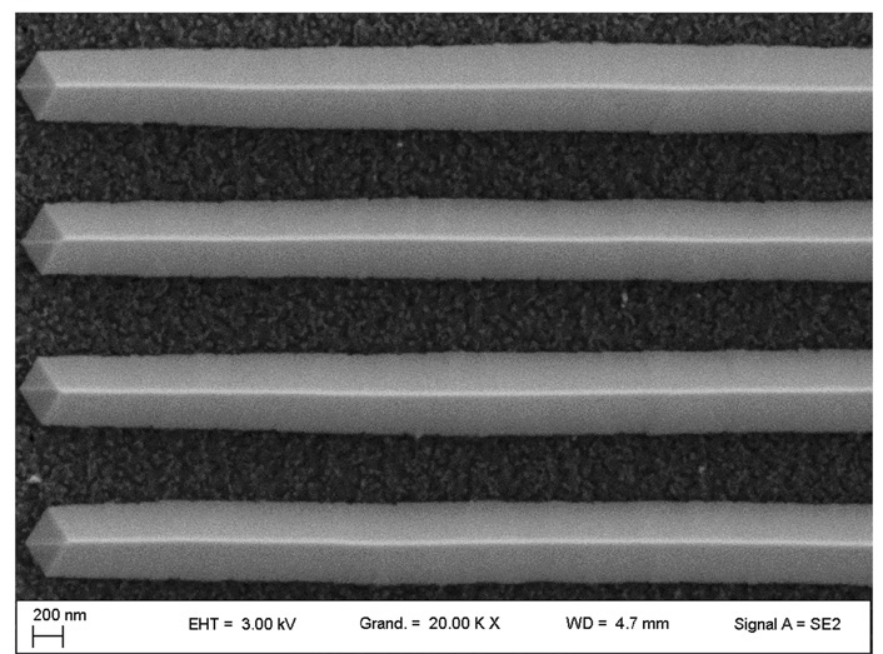

Fig. 1. SEM images of a hexagonal nano-pyramid and several $\langle 11-20\rangle$ oriented nano-ridges grown by NSAG.

beam XRD has been used to characterize individual AlGaN nanostructures, which were grown under the same growth conditions. Fig. 4 shows the asymmetric reflection $\left(\begin{array}{lll}1 & 0 & 0.5\end{array}\right)$ reciprocal space map of the AlGaN nano-ridge structure grown by NSAG. The AlGaN nanostructure is found to be elastically strained. Based on the angular positions of the diffraction peaks, the structural parameters of the AlGaN nanostructure have been calculated. The average aluminum atomic content both in the nanostructure and in the unpatterned area is found to be around 5\%, which is lower than the composition found at the apexes of the nano-pyramid and nano-ridge.

The HAADF TEM image of five InGaN multi-quantum wells (MQWs) grown on the semi-polar plane of a GaN nano-pyramid is shown in Fig. 5a. Unlike in the AlGaN/GaN growth, no clear evidence of quantum dot formation is observed at the apex of the nano-pyramid. We also found that growth facets of two different Miller's indices are formed on the InGaN/GaN nano-ridges. Fig. 5b shows growth facets of $(1-101)$ originating at the bottom of the nano-ridges and intersecting with the other growth facets of higher Miller's indices that extend to the top of the nano-ridges. To date, the reason for this formation of higher Miller's indices growth facets is not known. EDX analysis shows that as high as $10 \%$ indium has been incorporated at the intersection of the growth facets while only $6 \%$ indium has been incorporated in the InGaN MQWs. This phenomenon can be attributed to surface 
a

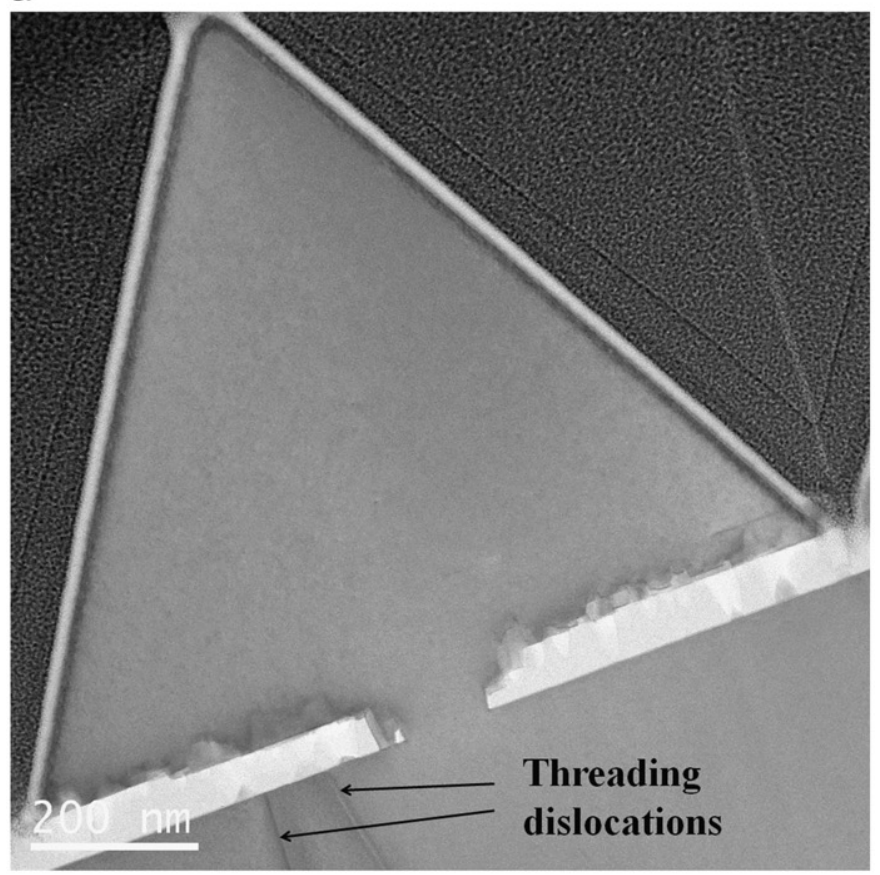

b

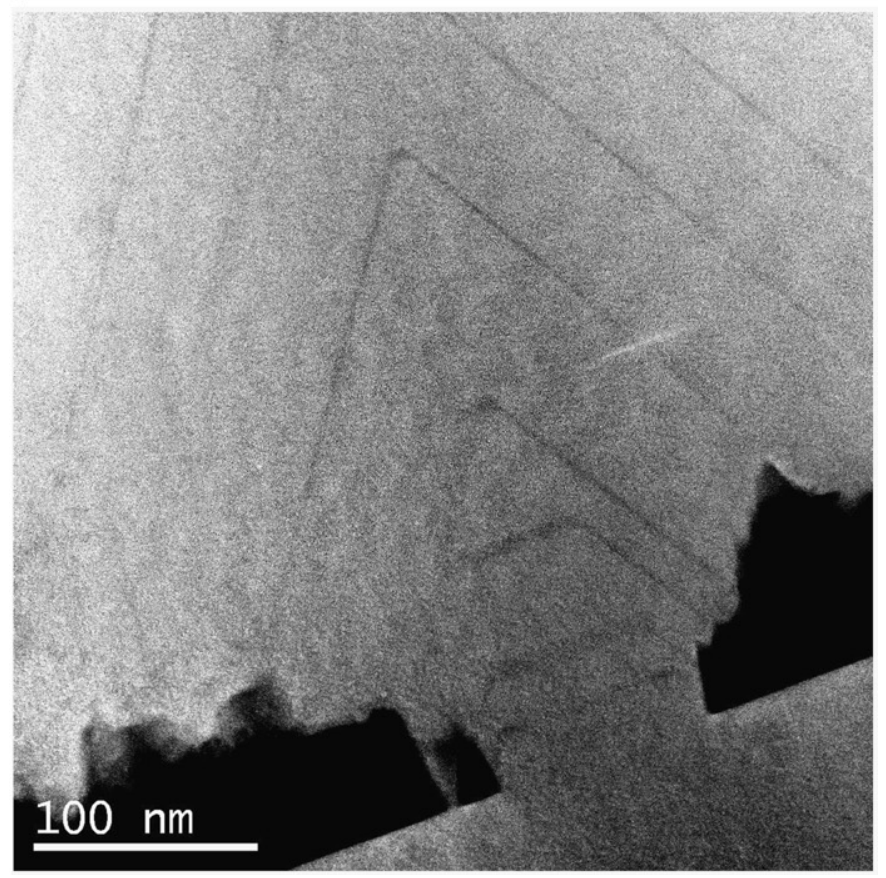

Fig. 2. (a) Cross-sectional bright field TEM image of AlGaN/GaN grown on a nanoridge showing absence of threading dislocations in the nanostructure. (b) Crosssectional HAADF TEM image near a nano-opening showing the growth evolution of the nanostructure by NSAG.

modifications (intersection of growth facets), which lower the chemical potential of nucleation. Note that high accumulation of indium at the intersection of the growth facets is essentially equivalent to the formation of a quantum wire structure along the nano-ridge direction.

Optical properties of the InGaN MQWs were investigated by room temperature CL spectra, as shown in Fig. 6. Strong emission at $422 \mathrm{~nm}$ and weak broad emission close to $600 \mathrm{~nm}$ are observed from the InGaN MQWs grown by NSAG. The weak broad emission is due to surface related defect from the nanostructure [13].

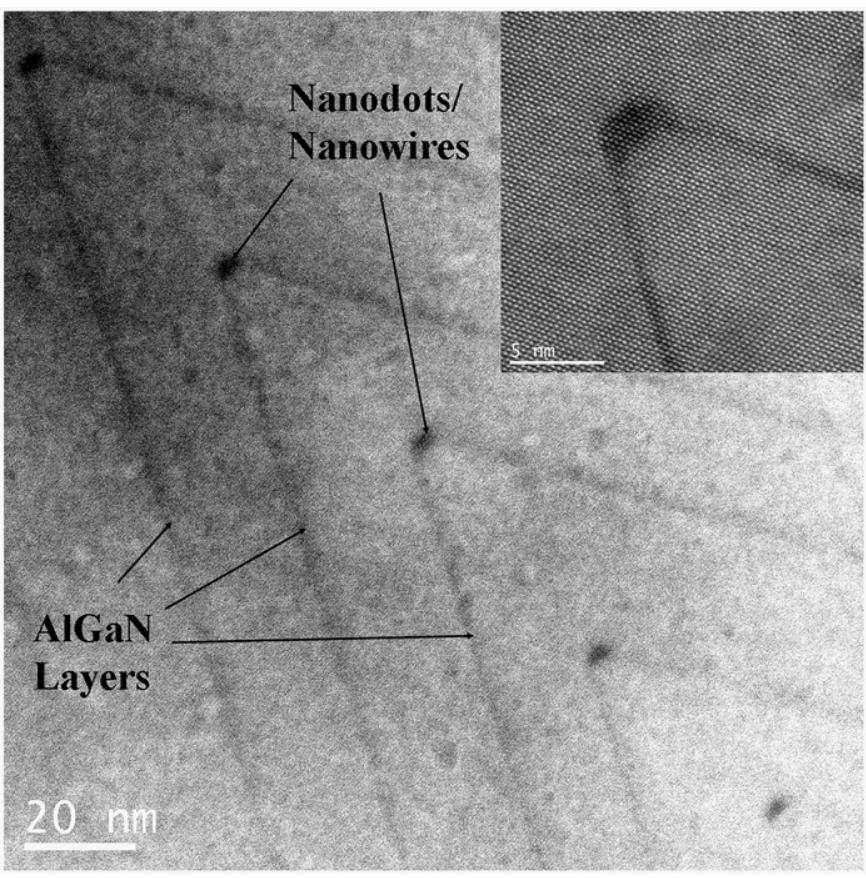

Fig. 3. Cross-sectional HAADF TEM image of AlGaN/GaN layers grown on a nanoridge showing sharp interfaces between the AlGaN and GaN epilayers and uniform growth. Inset shows a nanowire grown at the apex of a nano-ridge. The height and width of the nanowire are estimated to be $\sim 2.5$ and $\sim 6 \mathrm{~nm}$, respectively.

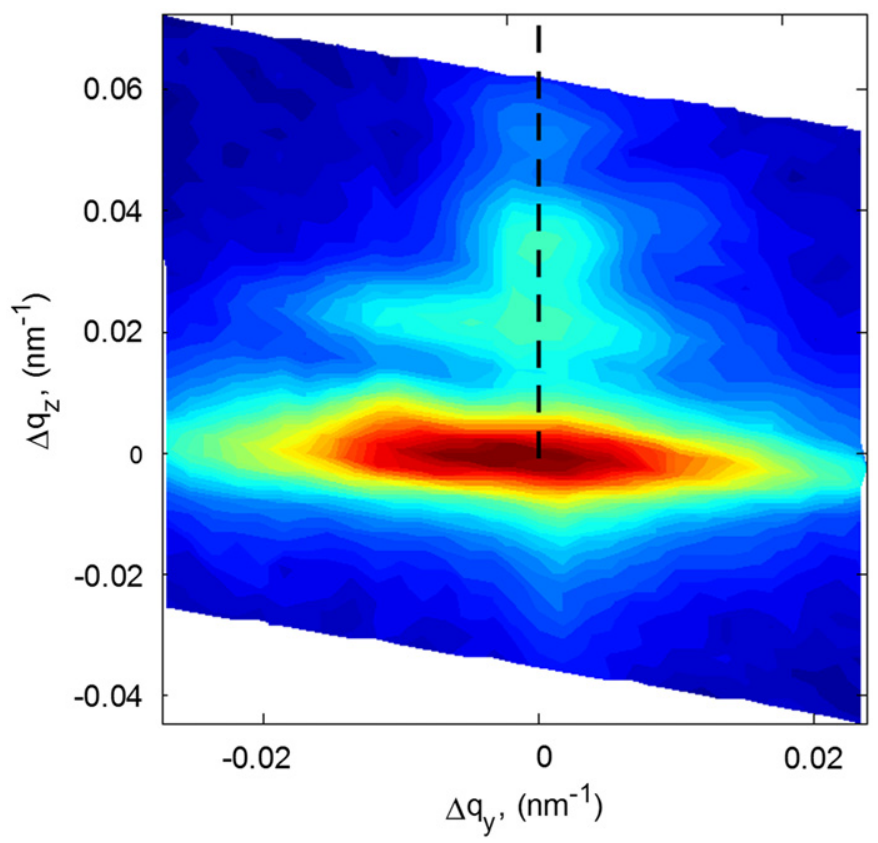

Fig. 4. ( $\left.\begin{array}{lll}1 & 0 & 5\end{array}\right)$ reciprocal space mapping of a AlGaN nano-ridge structure grown by NSAG. The strong peak in the center of the map corresponds to the GaN substrate. The signal from AlGaN consists of a weaker layer peak (right above the GaN peak) and thickness fringes. The incorporation of aluminum on the nanostructure has been estimated from the separation in reciprocal space between GaN and AlGaN peaks to be $5 \%$.

The wavelength of $\mathrm{CL}$ emission from the unpatterned area is $436 \mathrm{~nm}$. Intensity from the InGaN MQWs grown on the nanostructure is a few times higher in magnitude than that of the emission from the InGaN MQWs grown on the unpatterned area. The enhancement in $\mathrm{CL}$ emission is mainly attributed to a reduction in the non-radiative recombination centers associated 


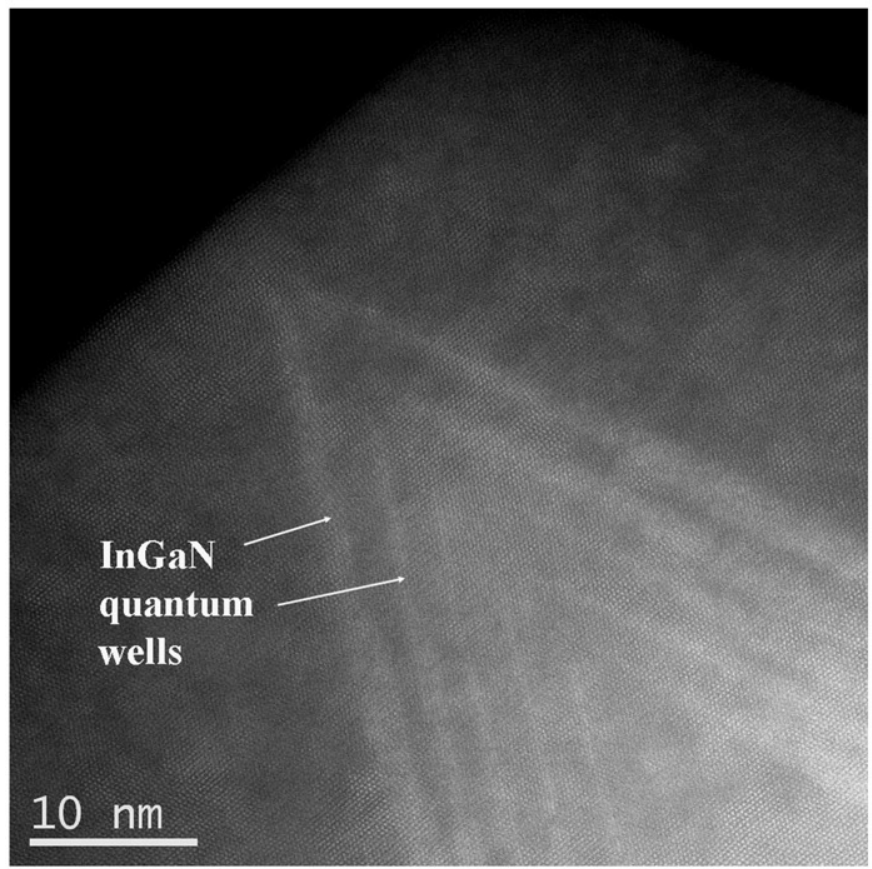

b

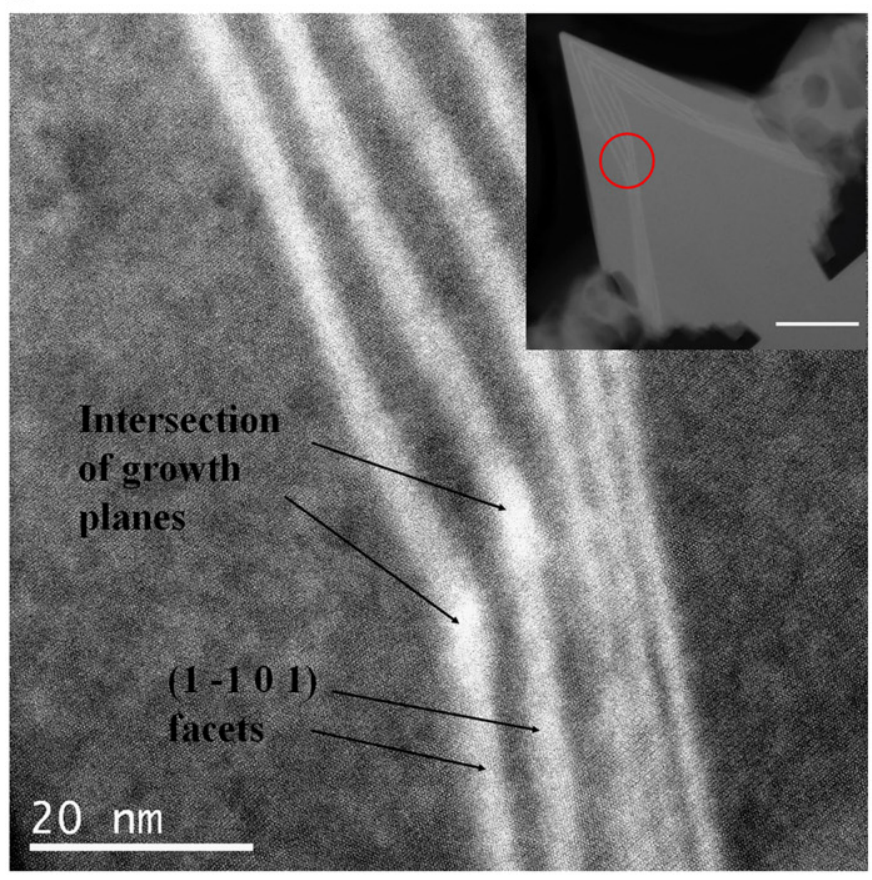

Fig. 5. (a) Cross-sectional HAADF TEM image of five-period InGaN/GaN MQWs grown on a semi-polar facet of the nano-pyramid. No clear evidence of quantum dots is observed at the top of the nano-pyramid. (b) Cross-sectional HAADF TEM image of InGaN/GaN MQWs showing change of growth facet close to the top of a nano-ridge. Inset shows the place where the intersection occurs. EDX analysis shows higher indium mole fraction at the intersection of the growth facets compared to the average value for the MQWs.

with threading dislocations as confirmed by the TEM results. However, the cause of the small blue-shift from the MQWs grown on the nanostructure is still unclear and further investigation will be required.

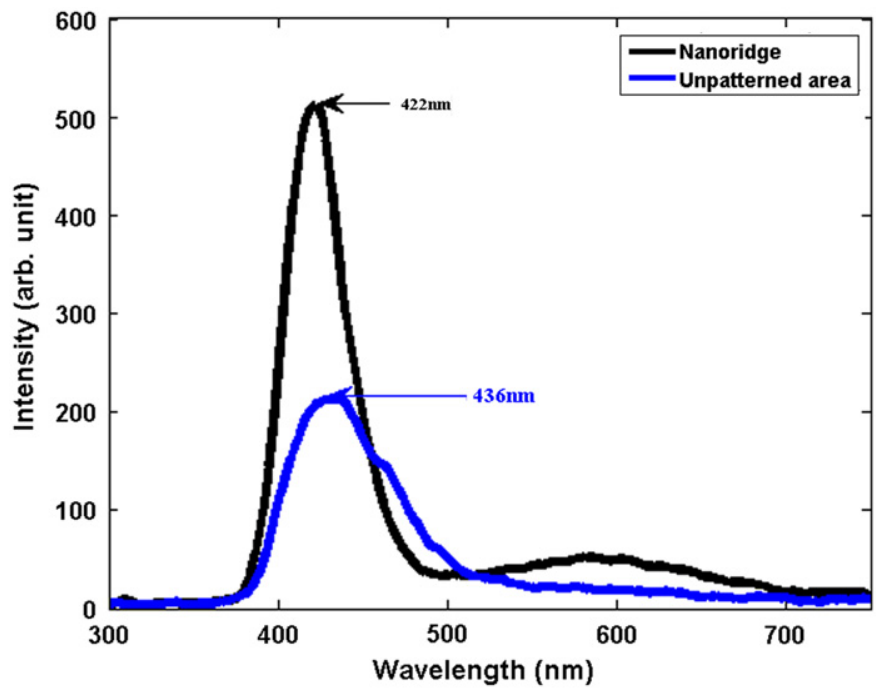

Fig. 6. Room temperature CL spectra of InGaN/GaN MQWs grown on nano-ridges and on the unpatterned area. InGaN MQWs grown on the nanostructure show higher CL intensity and $\sim 14 \mathrm{~nm}$ blue-shift of luminescence peak wavelength from that of the MQWs grown on the unpatterned area.

\section{Summary}

Nanodots, nanowires, and semi-polar quantum well structures of GaN-based material have been grown by NSAG. Structural and optical properties of these nanostructures have been investigated. The nanostructures grown by NSAG are found to be free of threading dislocations. AlGaN/GaN growth shows very uniform and sharp interfaces between layers. The nanostructures are very homogeneous in size. Aluminum mole fraction at the apex of the nanostructure and indium mole fraction at the intersection of the growth facets are higher than those for the respective side facets. InGaN MQWs grown on the nanostructure show enhanced $\mathrm{CL}$ emission as compared with the InGaN MQWs grown on the unpatterned area.

\section{References}

[1] Y. Arakawa, IEEE J. Sel. Top. Quantum Electron. 8 (2002) 823.

[2] D. Simeonov, E. Feltin, J.-F. Carlin, R. Butte, M. Ilegems, N. Grandjean, J. Appl. Phys. 99 (2006) 083509.

[3] K. Nishizuka, M. Funato, Y. Kawakami, Sg. Fujita, Y. Narukawa, T. Mukai, Appl. Phys. Lett. 85 (2004) 3122.

[4] B. Neubert, P. Bruckner, F. Habel, F. Scholz, T. Riemann, J. Christen, M. Beer, J. Zweck, Appl. Phys. Lett. 87 (2005) 182111.

[5] R. Waltereit, O. Brandt, A. Trampert, H.T. Grahn, J. Menniger, M. Ramsteiner, M. Reiche, K.H. Ploog, Nature London 406 (2000) 865.

[6] N. Akopian, G. Bahir, D. Gershoni, M.D. Craven, J.S. Speck, S.P. DenBaars, Appl. Phys. Lett. 86 (2005) 202104

[7] K. Tachibana, T. Someya, S. Ishida, Y. Arakawa, Phys. Status Solidi B 228 (2001) 187.

[8] V. Perez-Solorzano., A. Groning, M. Jetter, T. Riemann, J. Christen, Appl. Phys. Lett. 87 (2005) 163121.

[9] M. Feneberg, F. Lipski, R. Sauer, K. Thonke, T. Wunderer, B. Neubert, P. Bruckner, F. Scholz, Appl. Phys. Lett. 89 (2006) 171921.

[10] M. Funato, T. Kotani, T. Kondou, Y. Kawakami, Y. Narukawa, T. Mukai, Appl. Phys. Lett. 88 (2006) 261920.

[11] D. Zubia, S.H. Zaidi, S.R.J. Brueck, S.D. Hersee, Appl. Phys. Lett. 76 (2000) 858

[12] S. Gautier, C. Sartel, S. Ould-Saad, J. Martin, A. Sirenko, A. Ougazzaden, J. Cryst. Growth 298 (2007) 428.

[13] Q. Li, G.T. Wang, Nano Lett. 10 (2010) 1554. 